\title{
Chitosan-g-poly (acrylonitrile-co-acrylic acid) for wastewater treatment application
}

\author{
Nahla A. Mansour, Sahar M. Ahmed and Azza M. Mazrouaa* \\ Polymer Lab, Petrochemical Department, Egyptian Petroleum Research Institute, Nasr City, Cairo, 11727, Egypt
}

\begin{abstract}
Chitosan is a biodegradable natural based polymer obtained from chitin (N-deacetylated derivative), the second most abundant polysaccharide after cellulose and soluble in most organic acids. Graft copolymerization of poly (acrylonitrile-co-acrylic acid) onto chitosan has been successfully carried out using potassium persulfate as an initiator in an aqueous medium. The PAN and PAA homopolymer formed during the reaction were removed from the Chitosan grafted copolymer by Soxhlet extraction using ethanol as the solvent. The prepared graft copolymerization was characterized by Fourier transform infrared spectroscopy (FTIR), X-ray diffraction (XRD), and scanning electron microscopy (SEM) to confirm the formation of the copolymer. The prepared chitosan-g-copolymer at a ratio of 25:75\% of AN-co-AA was tested for wastewater treatment depending on various metal solutions at room temperature containing cadmium ions, times, and $\mathrm{pH}$. The optimal condition was found to be at $\mathrm{pH}=5$, time 120 min, and adsorbent dose $3 \mathrm{mg} / \mathrm{L}$.

The results revealed that the chitosan-g-copolymer prepared was excellent in removing the heavy metals than the copolymer alone. Hence, chitosan-g- poly- AN-co-AA could open the way for wastewater treatment. The thermal stability and the electrical conductivity for all prepared samples before and after grafing were measured. By studying the thermal stability at the different ratio of $\mathrm{AN}$ and $\mathrm{AA}$ in samples $\mathrm{CO}_{1}, \mathrm{CO}_{2}, \mathrm{Co}_{3}$, it was found that the most thermal stability sample ratio is $\mathrm{CO}_{3}$ due to increasing the ratio of $\mathrm{AN}$. While in sample $\mathrm{co}_{1}$ with a high ratio of $\mathrm{AA}$, the thermal stability decrease according to the fast decomposition of $-\mathrm{COOH}$ of acrylic acid. The conductivity was $3.85 \times 10^{-7}$ which is more than the copolymer without chitosan, which increases the electron density of the copolymer through the end group effect. As the result of $\sigma$ has a range $10^{-8} \mathrm{~S} / \mathrm{cm}^{-1} 10^{-6} \mathrm{~S} / \mathrm{cm}^{-1} \mathrm{so}$, all the prepared sample can be used as an electrostatic dissipation application.
\end{abstract}

Keywords: Chitosan-g-copolymer; poly (acrylonitrile-co-acrylic acid); radical polymerization; metal removal; wastewater treatment.

\section{Introduction}

Biopolymers were very interested in the removal of heavy metals from aqueous solution as an adsorbent ${ }^{1,2}$. Chitosan, in particular, is regarded as excellent applicants as it is environmentally friendly, low cost, and a broad source. However, its use as an efficient adsorbent is limited by the disadvantages of lousy chemical resistance and elevated crystallinity ${ }^{3}$. The number of chemical modifications dedicated to the application of chitosan materials using cross-linking, functional group grafting, and blending polymer or inorganic to remove metals and dyes from wastewater has increased rapidly ${ }^{4-6}$. Several carboxylated chitosan products have been recorded due to the significant chelating impacts of carboxyl groups. As a modifier

*Corresponding author: Azza M. Mazrouaa

Email address: azza_mazroua2005@yahoo.com DOI: http://dx.doi.org/10.13171/mjc9602001061110am material, polyacrylic acid (PAA) has drawn growing attention as it includes a carboxyl group in each repeated unit and favors metal ion adsorption ${ }^{4}$. In a homogeneous system, biodegradable and ultra-high content grafted chitosan-g-poly (acrylic acid) powder has been effectively synthesized and used as adsorbents to remove $\mathrm{Cu}$ (II) in aqueous solution. The peak adsorption capability of the Langmuir model was $210,13 \mathrm{mg} / \mathrm{g}$, showing a remarkable increase in chitosan adsorption ability after polygrafting (acrylic acid) ${ }^{7}$.

For the first time, the methacrylamide (MAM) was grafted on chitosan in the presence of ammonium persulfate (APS) as an initiator by the free radical method. The prepared sample of chitosan and chitosan-

Received October 3, 2019

Accepted November 15, 2019

Published January 6, 2020 
graft-poly (methacrylamide) were characterized ${ }^{8}$. Significant factors influencing graft copolymerization

such as reaction time, temperature and concentrations of APS, MAM and chitosan have been investigatedto get the greatest grafting parameters. The optimum grafting percentage and graft copolymerization yield values were obtained under the following circumstances: $(1 \mathrm{~g})$ chitosan, (4 g) MAM, (0.6 g) APS, (4 h) time and $\left(70^{\circ} \mathrm{C}\right)$ temperature.

The characteristics of chitosan-g-PMAM have been improved concerning chitosan, making it can be used as an adsorbent ${ }^{8}$. A chitosan-g-polyacrylonitrile copolymer was effectively synthesized using the initiator ceric ammonium nitrate through free radical polymerization. Analysis of TGA and DSC disclosed high thermal stability of the graft copolymer. Other research showed that the chitosan-g-polyacrylonitrile is an efficient adsorbent for the removal of $\mathrm{Cr}$ (VI) and $\mathrm{Cu}$ (II) metal ions from aqueous solutions. $\mathrm{Cr}$ (VI) and $\mathrm{Cu}$ (II) ion adsorption depend on the original metal ion concentration, adsorbent dose, $\mathrm{pH}$, and contact time. It has been discovered that chitosan-g-polyacrylonitrile is a useful adsorbent ${ }^{9}$. Cd (II) is one of the toxic metals to which attention has been paid. Because of its severe, dangerous effects on humans, animals, and crops, the removal of cadmium is gaining broad interest from both environmental and economic points of view. This heavy metal has caused severe soil and water contamination. Cadmium has been categorized as a lung, kidney, liver, and reproductive organs that affects human carcinogen and teratogen. A peak guideline concentration of 0.003 $\mathrm{mg} / \mathrm{L}$ for cadmium in drinking water was set by the World Health Organization (WHO) ${ }^{10}$. To remove copper and cadmium ions from synthetic industrial wastewater, chitosan with nylon 6 membranes was assessed as adsorbents. The percentage of removal of copper increased with an increase in the $\mathrm{pH}$ from 3 to 5 . In the case of cadmium containing wastewater, the maximum removal of metal occurred at $\mathrm{pH}$ 5. The uptake amount of $\mathrm{Cu}^{2}+$ ions on chitosan increased rapidly with increasing contact time from 0 to $360 \mathrm{~min}$ and then reaches equilibrium after $360 \mathrm{~min}$; the equilibrium constant for copper and cadmium ions is more or less the same for the adsorption reaction ${ }^{11}$.
Thus, in our present study, the copolymerization of acrylonitrile (AN) with acrylic acid (AA) comonomer was prepared through free radical polymerization to form poly (AN-co-AA). Since the development of the polymer properties becomes a crucial challenge of the research field for use in various industrial applications. Also, we report on the Graft copolymerization of poly (acrylonitrile-co-acrylic acid) onto chitosan at a specific ratio. Adsorption behavior and performance of the CS-g-poly (AN-co-AA) were determined by various effecting parameters like contact time, initial concentration, and $\mathrm{pH}$ value in the removal of $\mathrm{Cd}$ (II) from aqueous solution.

\section{Materials and methods}

As reported ${ }^{12}$, Chitosan was prepared from shrimp shells with $110 \mathrm{kDa}$ of molecular weight and $85 \%$ of the degree of deacetylation in our lab. Acrylic acid (AA) was purchased from Koch-Light Laboratories; potassium persulfate $\left(\mathrm{K}_{2} \mathrm{~S}_{2} \mathrm{O}_{8}\right)$ and acrylonitrile (AN) were obtained from Sigma-Aldrich and used after get rid of the inhibitor by using $\mathrm{NaOH}$. All solution was prepared using double distilled water. Dimethylformamide DMF obtained from Piochem, ethanol as a solvent from El Nasr Pharmaceutical Chemicals Co., and other reagents using as it is.

\subsection{Preparation Poly (acrylonitrile co-acrylic acid) preparation}

Potassium persulfate $\left(\mathrm{K}_{2} \mathrm{~S}_{2} \mathrm{O}_{8}\right)$ was dissolved as an initiator in DMF: water mixture at the beginning with stirring at volume ratio 50:50. The mixture was then added to monomers (AN, AA) and stirred in a threenecked flask for $30 \mathrm{~min}$, and the temperature of the bath was set at $60^{\circ} \mathrm{C} \pm 2{ }^{\circ} \mathrm{C}$. The poly (AN-co-AA) was synthesized by free radical polymerization with code $\mathrm{CO}_{1}, \mathrm{CO}_{2}$ and $\mathrm{CO}_{3}$ respectively with different ratio of 25:75 percent, 50:50 percent and 75:25 percent. To remove the AA and AN monomers, the product was completely extracted by washing with ethanol and 3 times with distilled water. The copolymers were then poured for 48 hours in a Petri platter in a vacuum oven at $60^{\circ} \mathrm{C}$ and then filmed ${ }^{13}$ as shown in Scheme 2.

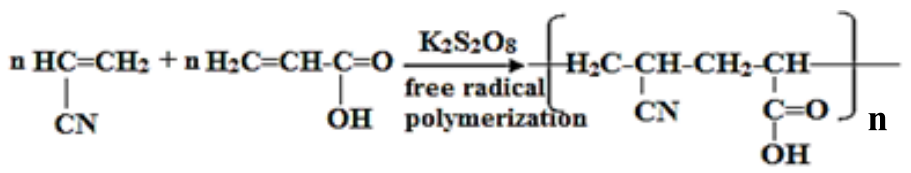

Scheme 1. Poly (acrylonitrile co-acrylic acid)

\subsection{Chitosan grafted poly (acrylonitrile-co-acrylic acid) Preparation}

Based on previous research ${ }^{7}$, the CS-g-poly (AN-AA) was prepared. $0.1 \mathrm{mg}$ of $\mathrm{Cs}$ was dissolved in $25 \mathrm{ml}$ of
$5 \%$ acetic acid, then take 0.1 of $\mathrm{K}_{2} \mathrm{~S}_{2} \mathrm{O}_{8}$ in the solution of $\mathrm{CS}$ for $10 \mathrm{~min}$ with magnetic stirring in the reflux. After that, the monomers of $\mathrm{AN}$ and $\mathrm{AA}$ were added, with ratio $25: 75\left(\mathrm{Co}_{1}\right) \%$ heated to $60^{\circ} \mathrm{C}$ and kept stirring for 
4hr. Removing the AA and AN monomer need to completely extract the product by washing with ethanol and 3 times with distilled water. The resulting mixture was then cooled to room temperature, and the product was poured into the petri dish and left to evaporate to give code $\mathrm{CO}_{4}$ to the film.

\subsection{Characterization of prepared compounds}

The chemical structures of the copolymers prepared with different ratio and chitosan -g- poly (AN-co-AA acid) were confirmed by Fourier transforms infrared spectroscopy by Perkin- Elmer 1650 in the range of $4000-500 \mathrm{~cm}^{-1}$ where the $\mathrm{KBr}$ technique was used. Thermogravimetric analysis TGA was performed for all prepared samples by using a Shimadzu TGA-50H instrument. The rate of heating was $10^{\circ} \mathrm{C} / \mathrm{min}$ up to $800^{\circ} \mathrm{C}$ under a nitrogen atmosphere. The evaluations of electrical conductivity DC were measured using a fourprobe technique and analyze using Keithley 6517A. It has to be that the sample cut $1 \mathrm{mmx} 1 \mathrm{mmx} 1 \mathrm{~mm}$ was kept in the middle of two copper electrodes, where two Keithley electrometer terminals were associated accordingly.

\subsection{Adsorption reactions}

Adsorption reactions to removal Cadmium are using the prepared polymers:

All experiments were performed at room temperature using batch technique. Dissolve a suitable amount of $\mathrm{CdCl}_{2}$ in deionized water and subsequently diluting it to the required concentrations to prepare a stock solution of ( $1.0 \mathrm{~g} / \mathrm{L}) \mathrm{Cd}$ (II) ions. To avoid the formation of metal hydroxide and to come to the metal ion again to the dissolved state, the stock solutions were acidified to required $\mathrm{pH}$ with concentrated $\mathrm{HCl}$. The $\mathrm{pH}$ values were adjusted from 2 to 9 , with $0.1 \mathrm{~N} \mathrm{NaOH}$ and $0.1 \mathrm{~N} \mathrm{HCl}$. Varying the adsorbent dose, the $\mathrm{pH}$ of the solution and time of shaking the adsorbent metal solution was used to investigate the cadmium metal removal. The stopper bottles were adjusted at room temperature by stirring at a fixed speed, $200 \mathrm{rpm}$ for $180 \mathrm{~min}$. The samples were taken at definite time intervals at $(5,10,20,30,60,90$ and180 $\mathrm{min}$ ). After adsorption, the above adsorption systems were centrifuged for $15 \mathrm{~min}$ at $3000 \mathrm{r} / \mathrm{min}$, and then $10 \mathrm{ml}$ of each supernatant aliquot was filtered and analyzed for remaining $\mathrm{Cd}$ (II) concentration by an atomic absorption spectrophotometer. Metal solutions that did not contain sorbent served as controls ${ }^{10}$.

\section{Results and Discussions}

\subsection{Chitosan and grafted copolymer} characterization

\subsubsection{Fourier transforms infrared spectroscopy}

FTIR spectra for Cs, (AN-co-AA) copolymer and $\mathrm{CO}_{4}$ are shown in (Figure1). In chitosan, it was appeared strong, and broadband appeared at 3441.71; corresponding to the vibration of $-\mathrm{NH}_{2}$ group and carboxylic acid $-\mathrm{OH}$ stretch, a band related to $\mathrm{C}-\mathrm{H}$ stretching groups are shown at $2921.5 \mathrm{~cm}^{-19}$, the stretching of the $(\mathrm{C}=\mathrm{O})$ at $1646.61 \mathrm{~cm}^{-1}$ and at $1423.32 \mathrm{~cm}^{-1}$ according to $\mathrm{C}-\mathrm{N}$ bond stretching.

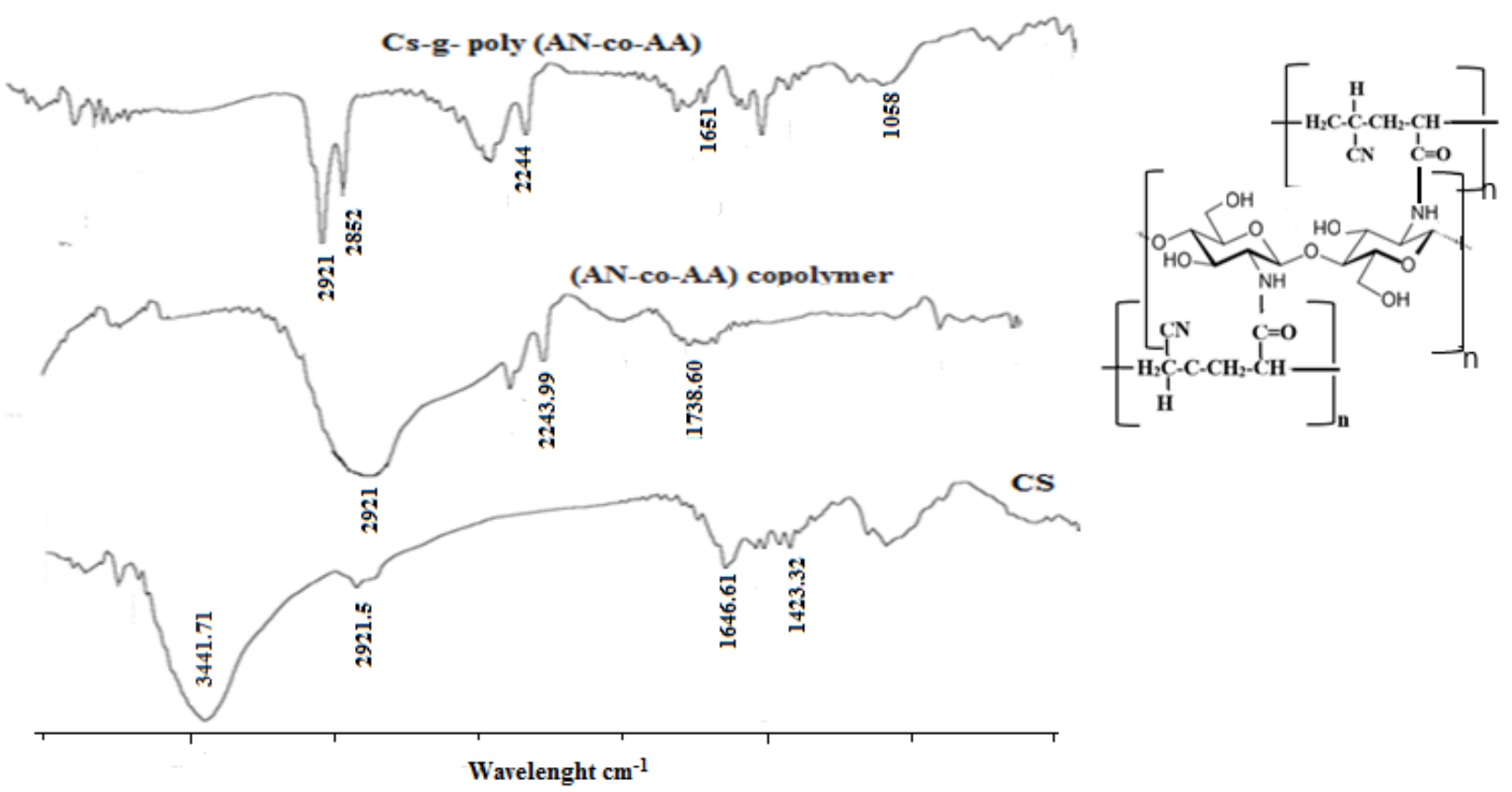

Figure 1. FTIR for $\mathrm{Cs}$, $\mathrm{CO}_{2}$, and $\mathrm{CO}_{4}$ 
FTIR spectra for (AN-co-AA) copolymer has an absorption bands at $2243.99 \mathrm{~cm}^{-1}$, and $1738.60 \mathrm{~cm}^{-1}$ indicates the existing of $\mathrm{C} \equiv \mathrm{N}$ group for $\mathrm{AN}, \mathrm{C}=\mathrm{O}$ for AA stretching and peaks in the range between 2500$3000 \mathrm{~cm}^{-1}$ for carboxylic acid $-\mathrm{OH}$ stretch respectively 14. At the same time, the peaks of $\mathrm{C}=\mathrm{C}$ at $1500 \mathrm{~cm}^{-1}$ disappeared; this confirms that the copolymerization was occurring.

The sample co $_{4}$ which prepared by reaction of $\mathrm{NH}_{2}$ groups of $\mathrm{Cs}$ and $-\mathrm{COOH}$ groups of $\mathrm{AA}$ of copolymer,

\subsubsection{XRD}

XRD pattern of $\mathrm{Cs}, \mathrm{CO}_{1}$ and $\mathrm{CO}_{4}$ Was shown in (Figure 2). The band in chitosan-g-(AN-co-AA) spectrum showed the shifted of $2 \theta$ due to the grafting of coploymer onto the chitosan backbone. The XRD patterns of chitosan changed after grafted and shifted to a lower angle $(2 \theta=17.81)$. Acharyulu et al. reported that the intensity it appears as a band at $1651 \mathrm{~cm}^{-1}$ which attributed to CONH groups. It is expected that there will be a reaction between $\mathrm{NH}_{2}$ groups of $\mathrm{Cs}$ and $\mathrm{C}=\mathrm{C}$ of copolymer which has disappeared. The peaks at (2921- 2852.07 $\mathrm{cm}^{-1} \mathrm{~m}$ or $\mathrm{s}$ ) (C-H stretching) was appearing with increasing the intensity beside to the presence of the peaks of the $\mathrm{C} \equiv \mathrm{N}$ group for copolymer and 2245 $\mathrm{cm}^{-1}$ and $1058 \mathrm{~cm}^{-1}$ of C-OH group for Cs. The presence of these functional groups plays a vital role in $\mathrm{Cd}(\mathrm{II})$ ions adsorption ${ }^{15}$.

of the crystalline peak of the grafted polymers decreased or shifted with the extent of grafting ${ }^{16}$. Meanwhile, the copolymer shifted to a higher angle at $(2 \theta=27.39)$ after grafted. The changes were attributed to the destruction of hydrogen bonds between hydroxyl and amino groups after chemical modification ${ }^{17}$.

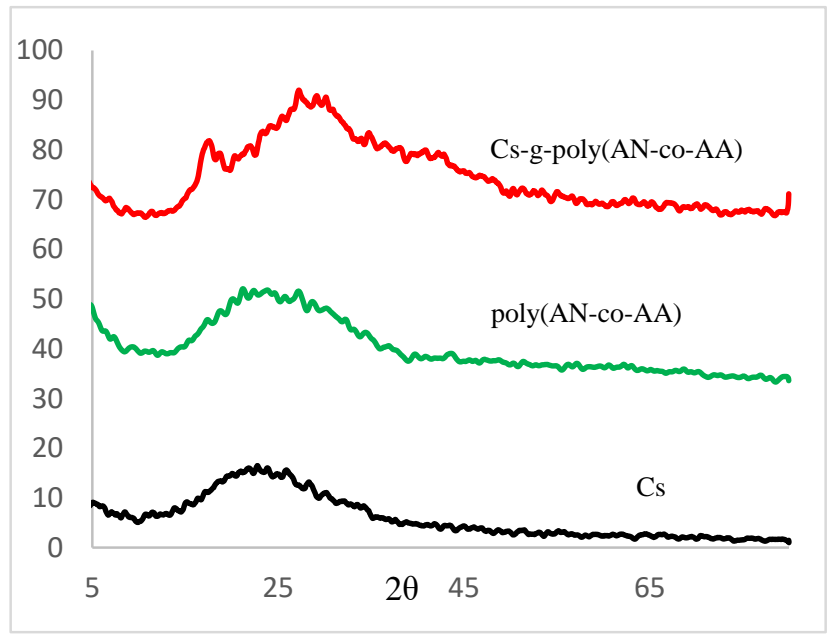

Figure 2. XRD of chitosan and $\mathrm{Co}_{4}$

\subsubsection{SEM}

As shown in the (Figure 3), it is noteworthy that, owing to a powerful inter-and intra-hydrogen bonding, chitosan introduced a soft and nonporous on the surface. On the contrary, the surface of $\mathrm{CO}_{4}$ has more visible pore structure.
The chemical modification of raw chitosan using by the grafting skeleton affected the surface structure of the copolymer, making the $\mathrm{CO}_{4}$ have high porosity lead to higher adsorption ${ }^{8}$.

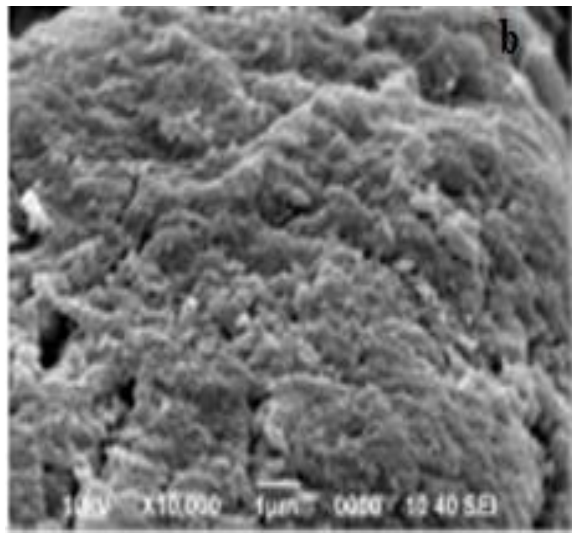

Figure 3. SEM for $\mathrm{Cs}$ and $\mathrm{CO}_{4}$ 


\subsection{Factors Influence of Cd (II) ion adsorption}

(Figure $4 \mathrm{a}-\mathrm{c}$ ) showed the adsorption effectiveness of the adsorbent depending on the solution's $\mathrm{pH}$, adsorbent dosage and contact time at room temperature) ${ }^{18}$.

\subsubsection{Effect of $\mathbf{p H}$}

The aqueous solution's $\mathrm{pH}$ value is a significant control parameter in the method of adsorption. These $\mathrm{pH}$ values influence the adsorbent surface charge, the degree of ionization and adsorbate speciation during adsorption. The studies were performed at separate initial $\mathrm{pH}$ varying from 2 to 9 in order to assess the influence of this parameter on the adsorption. Also, the zero-point charge $\left(\mathrm{pH}_{\mathrm{ZPC}}\right)$ for the $\mathrm{CO}_{4}$ was determined around $\mathrm{pH}=4.9$. $\mathrm{CO}_{4}$ performed the experiment with an initial
$20 \mathrm{mgL}^{-1}$ cadmium ion concentration containing $3 \mathrm{~g}$ of adsorbent $/ \mathrm{L}$ at room temperature with a $2 \mathrm{~h}$ contact time.

The concentration of $\mathrm{H}^{+}$ions was high in acidic media. This led to the growth of positive charge on $\mathrm{CO}_{4}$ 's active sites, as well as a contest between $\mathrm{Cd}$ (II) ions and $\mathrm{H}^{+}$in the bulk of the solution to be attached to the copolymer's active binding sites. Therefore, reducing the positive surface charge results in lowering the electrostatic repulsion between surface ions and metal ions. In the meantime, Cd (II) adsorption is declining in the alkaline medium, owing to the creation of soluble hydroxyl complexes. The outcome in (Figure 4a) shows that at an equilibrium $\mathrm{pH}$ of 5 , the highest removal of $\mathrm{Cd}$ (II) was achieved ${ }^{19}$.

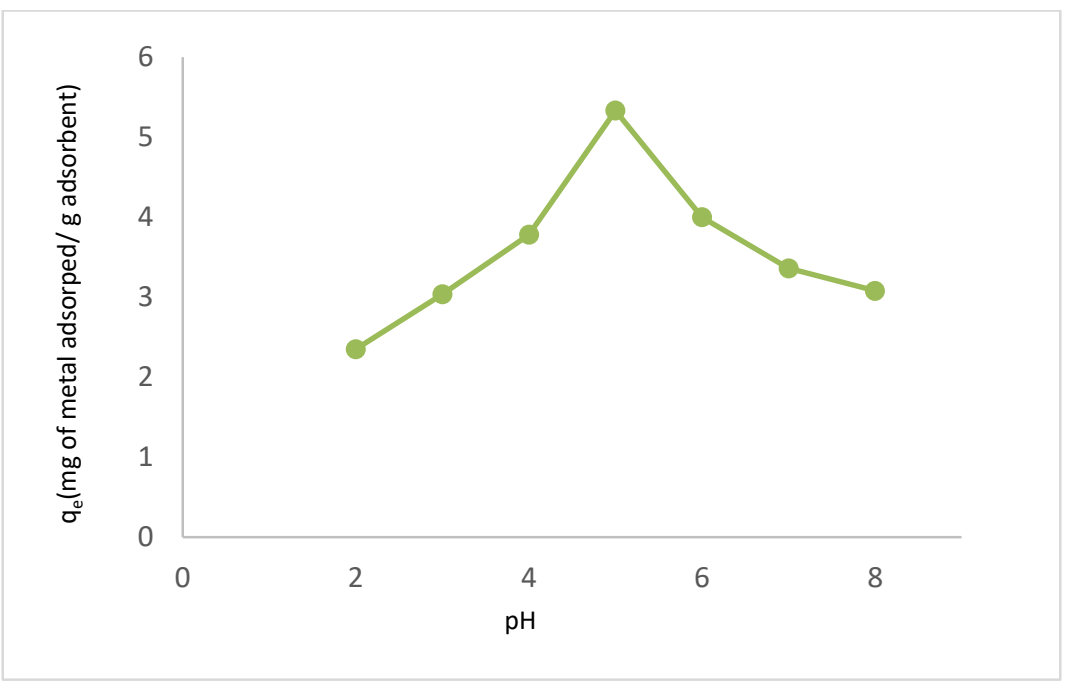

Figure 4a. The effect of $\mathrm{pH}$ on the desorption capacity of $\mathrm{co}_{4}$ (the $\mathrm{Cd}(\mathrm{II})$ initial concentration, contact time, and amount of adsorbent was $20 \mathrm{mg} / \mathrm{L}, 2 \mathrm{~h}$, and $3 \mathrm{~g} / \mathrm{l}$, respectively).

\subsubsection{Effect of Contact Time}

The tests on adsorption were conducted at different times of contact. (Figure 4b) demonstrates the impact of contact time on $\mathrm{Cd}$ ion adsorption at an original concentration of $20 \mathrm{mg} \mathrm{L}^{-1}$, adsorbent dose $(3 \mathrm{~g} / \mathrm{L})$, at room temperature, $\mathrm{pH}=5$ at contact time up to $180 \mathrm{~min}$.

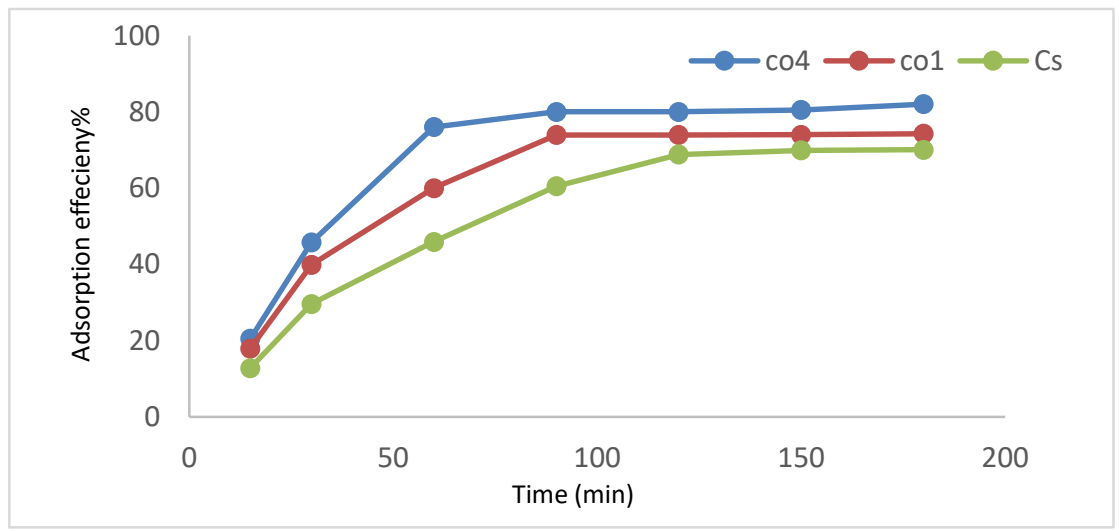

Figure $4 \mathbf{b}$. The effect of time on the adsorption efficiency of $\mathrm{Cs}, \mathrm{co}_{1}$ and $\mathrm{co}_{4}$ (the initial concentration, $\mathrm{pH}$ and amount of adsorbent were $20 \mathrm{mg} / \mathrm{L}, 5$, and $3 \mathrm{~g} / \mathrm{L}$, respectively) 
The adsorption capacity of co4 was quite larger than that of co1 or Cs within $180 \mathrm{~min}$, confirming that the introduction of copolymer (AN-co-AA) increasing the porosity of $\mathrm{CO}_{4}$ as seen in (Figure.3) which are favorable for improving adsorption capacity. For the first $60 \mathrm{~min}$, the $\mathrm{Cd}$ adsorption rate is high, and after about $120 \mathrm{~min}$, equilibrium is finally created. The abundance of active sites on the adsorbent surface could be attributed to the rapid adsorption of $\mathrm{Cd}$ ions at the initial stages of contact time.

The adsorption subsequently became less effective with the gradual occupancy of these sites. A further rise in contact time did not improve adsorption, so for further studies, the optimum contact time for the adsorbent was chosen as $120 \mathrm{~min}$. The results stated that 70.25, 74.05 and 82.00 percent respectively, are found to be the removal effectiveness of $\mathrm{Cs}, \mathrm{CO}_{1}$ and $\mathrm{CO}_{4}$. $\mathrm{CO}_{4}$ 's removal effectiveness is higher than the other polymers.

\subsubsection{Effect of Adsorbent Dose}

One of the significant parameters of adsorption is the dose of adsorbents. It can be seen that the amount of adsorbents increases with the adsorption. This can be explained by increased accessibility at a large quantity of the adsorbent of the active sites or surface area. The proportion of adsorption rises from the copolymer doses of 1.0-5.0 g / L. (Figure 4c) showed the adsorbent dose effect on $\mathrm{Cd}$ ions adsorption. When adsorbent was reached in equilibrium, there was no significant change in the addition of the adsorbent dose. Thus, for the maximum removal percentage $\mathrm{Cd}$ (II), the optimum adsorbent dose was $3 \mathrm{mg} / \mathrm{L}$. When adsorbent was reached equilibrium, further addition of adsorbent dose did not cause any significant change. Thus the optimum dose of the adsorbent for the maximal removal percent Cd (II) was $3 \mathrm{mg} / \mathrm{L}$.

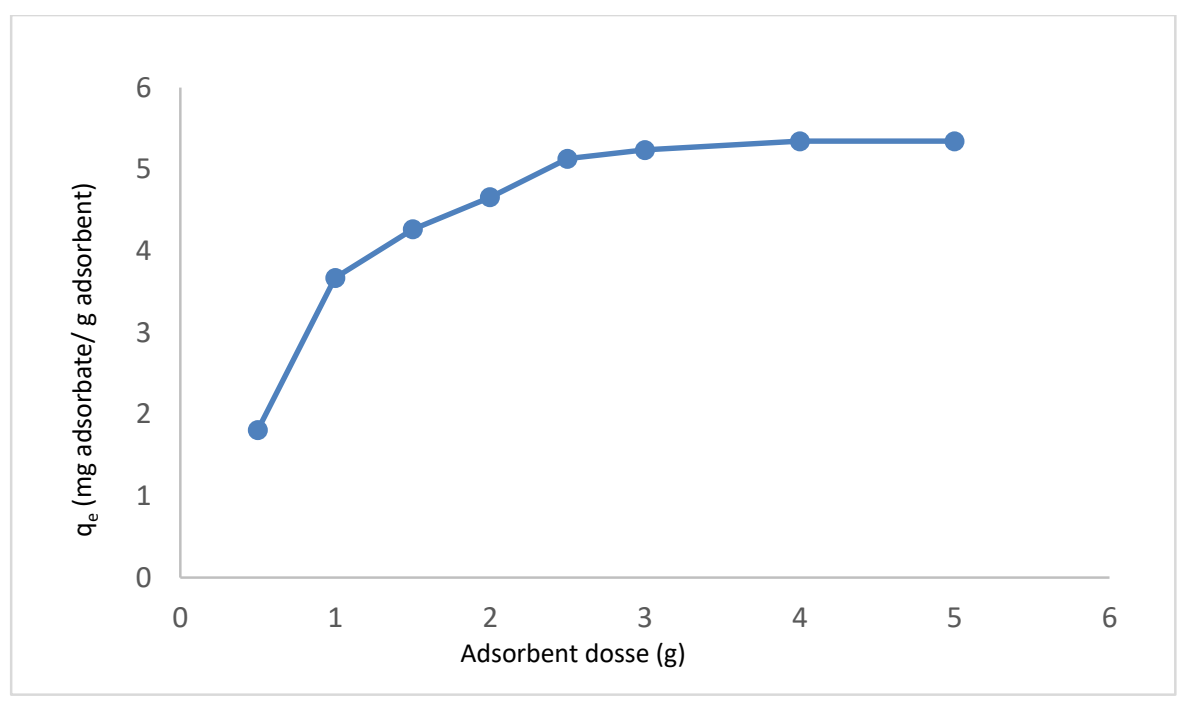

Figure 4c. The effect of adsorbent dose on the removal efficiency of $\mathrm{Cd}(\mathrm{II})$ (at $\mathrm{pH} 5$, the initial concentration of $\mathrm{Cd}$ was $20 \mathrm{mg} / \mathrm{L}$ and contact time, $2 \mathrm{~h}$ )

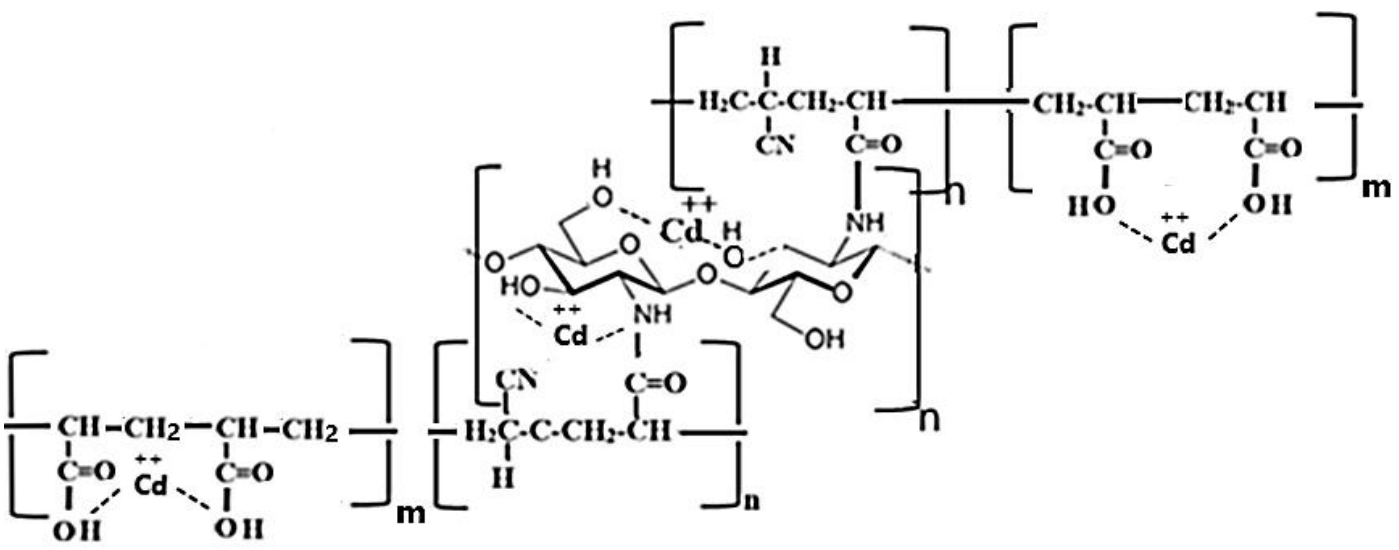

Scheme 2. Mechanism of Cadmium adsorption by Chitosan grafted poly (acrylonitrile-co-acrylic acid) 


\subsubsection{Mechanism of Cadmium adsorption}

In the adsorption of $\mathrm{Cd}(\mathrm{II})$ ions, the presence of functional groups $(\mathrm{OH}, \mathrm{NH}$ and $\mathrm{COO})$ as mentioned in FTIR plays an important role. The coordinate bond with metallic ions is initiated by the amine group. The bond is formed between the free electron of the nitrogen in the amine group and the void orbitals of the metal. Nevertheless, the introduction of new functional groups $\left(-\mathrm{COO}^{-}\right)$on the chitosan surface by grafting on copolymer AN-co-AA leads to an increase in sites available. E. Guibal ${ }^{15}$ stated that by introducing new functional groups, the density of sorption sites on the chitosan surface increased. On the other hand, the hydroxyl $(\mathrm{OH})$ and amino $(\mathrm{NH})$ groups may form several complexes with metal cations, as shown in Scheme 2.

\subsubsection{TGA}

Thermogravimetric analysis (TGA) was used to determine the weight loss percentage at the rate of heating was $10^{\circ} \mathrm{C} / \mathrm{min}$ up to $800^{\circ} \mathrm{C}$ under a nitrogen atmosphere. (Figure 5) shows the thermal analyses curve for $\mathrm{CO}_{1}, \mathrm{CO}_{2}, \mathrm{CO}_{3}, \mathrm{CO}_{4}$ and $\mathrm{Cs}$. The first stage for all samples is at a temperature between $40-120^{\circ} \mathrm{C}$ due to evaporating the moisture while in the case of $\mathrm{CO}_{4}$ and $\mathrm{Cs}$ the temperature increases in this stage to reach to 180 and $220^{\circ} \mathrm{C}$ due to loss of moisture adsorbed by the polysaccharide and any organic solvents. It appeared that $\mathrm{Cs}$ and co4 decomposed faster than poly (AN-coAA) between 220 and $450^{\circ} \mathrm{C}$. It indicates the thermal stability of chitosan is increased after the grafting of poly (AN-co-AA) due to the strong hydrogen bond $\left(\mathrm{NH}_{2}, \mathrm{OH}\right)$ of chitosan with copolymer ${ }^{17}$. On the other hand, by studying the thermal stability at the different ratio of $\mathrm{AN}$ and $\mathrm{AA}$ in samples $\mathrm{CO}_{1}, \mathrm{CO}_{2}, \mathrm{CO}_{3}$, it was found that the most thermal stability sample ratio is $\mathrm{CO}_{3}$ due to increasing the ratio of AN as shown in Table 1. While in sample $\mathrm{CO}_{1}$ with a high ratio of AA, the thermal stability decrease according to the fast decomposition of $-\mathrm{COOH}$ of acrylic acid.

Table 1. Thermal parameters of the prepared samples as a function of $10 \% \& 50 \%$ weight loss, and char residue at $700^{\circ} \mathrm{C}$.

\begin{tabular}{|c|c|c|c|}
\hline Sample code & $\begin{array}{c}\text { Temp at 10\% } \\
\text { Weight loss }\end{array}$ & $\begin{array}{c}\text { Temp at 50\% } \\
\text { Weight loss }\end{array}$ & $\begin{array}{c}\text { Char residue at } \\
\mathbf{7 5 0}^{\circ} \mathbf{C}\end{array}$ \\
\hline co1 & 233 & 290 & 5.63 \\
\hline co2 & 188 & 348 & 21.70 \\
\hline co3 & 209 & 433 & 33.88 \\
\hline co4 & 218 & 273 & 6.08 \\
\hline Cs & 197 & 343 & 2.07 \\
\hline
\end{tabular}

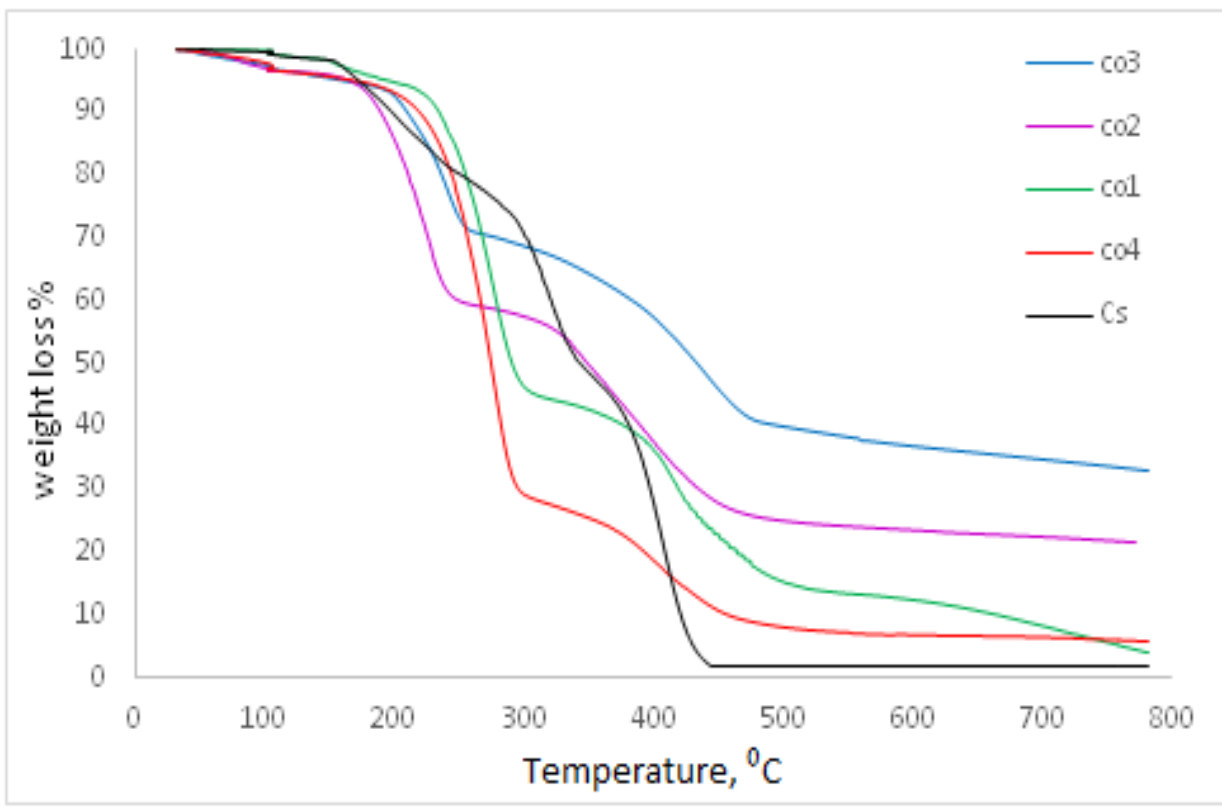

Figure 5. TGA for $\mathrm{CO}_{1}, \mathrm{CO}_{2}, \mathrm{CO}_{3}, \mathrm{CO}_{4}$ and $\mathrm{Cs}$ 


\subsection{Electrical conductivity}

Here, the electrical conductivity of different ratio of copolymers $\mathrm{CO}_{1}, \mathrm{CO}_{2}, \mathrm{CO}_{3}$ and $\mathrm{CO}_{4}$ were studied. From the study of the relationship between the current(I) and the volt $(\mathrm{V})$, the prepared samples give a straight line passing the starting point, so it is Ohmic relation as in (Figure 6a).

The electrical conductivity $(\sigma)$ of AN-co-AA with different ratio $\mathrm{CO}_{1}, \mathrm{CO}_{2}, \mathrm{CO}_{3}$ and $\mathrm{CO}_{4}$ was investigated at room temperature using a four-probe method and analyzed with Keithley 6517A shown in (Figure 6b). The PAN is no conducting polymer, and its electrical conductivity at room temperature lies between $10^{-8}$ to $10^{-11} \mathrm{~S} \mathrm{~cm}^{-1}$ related to the previous study ${ }^{20}$. In this work, the data showed that $\sigma$ of the copolymer depends on the ratio of AN and AA. By measuring $\sigma$ for the different ratio of copolymer, it was found that the conductivity increased by increasing the ratio of AA due to increasing the number of mobile ions. The electrical conductivity was $2.12 \times 10^{-7}, 6.89 \times 10^{-8}$ and $2.02 \times 10^{-8}$ for $\mathrm{Co}_{1}, \mathrm{CO}_{2}$ and $\mathrm{CO}_{3}$ respectively. While is mentioned from previous studies, pure chitosan films exhibited an average conductivity of $1.91 \times 10^{-7} \mathrm{~S} / \mathrm{cm}^{-121}$. From the results, we choose the best ratio, which gave the highest $\sigma$ and prepared to graft chitosan in situ with $\mathrm{CO}_{4}$. The conductivity was $3.85 \times 10^{-7}$ which is more than the copolymer without chitosan, which increases the electron density of the copolymer through the end group effect. As the result of $\sigma$ has a range $10^{-8} \mathrm{~S} / \mathrm{cm}^{-1} 10^{-6}$ $\mathrm{S} / \mathrm{cm}^{-1} \mathrm{so}$, all the prepared sample can be used as an electrostatic dissipation application ${ }^{22}$.
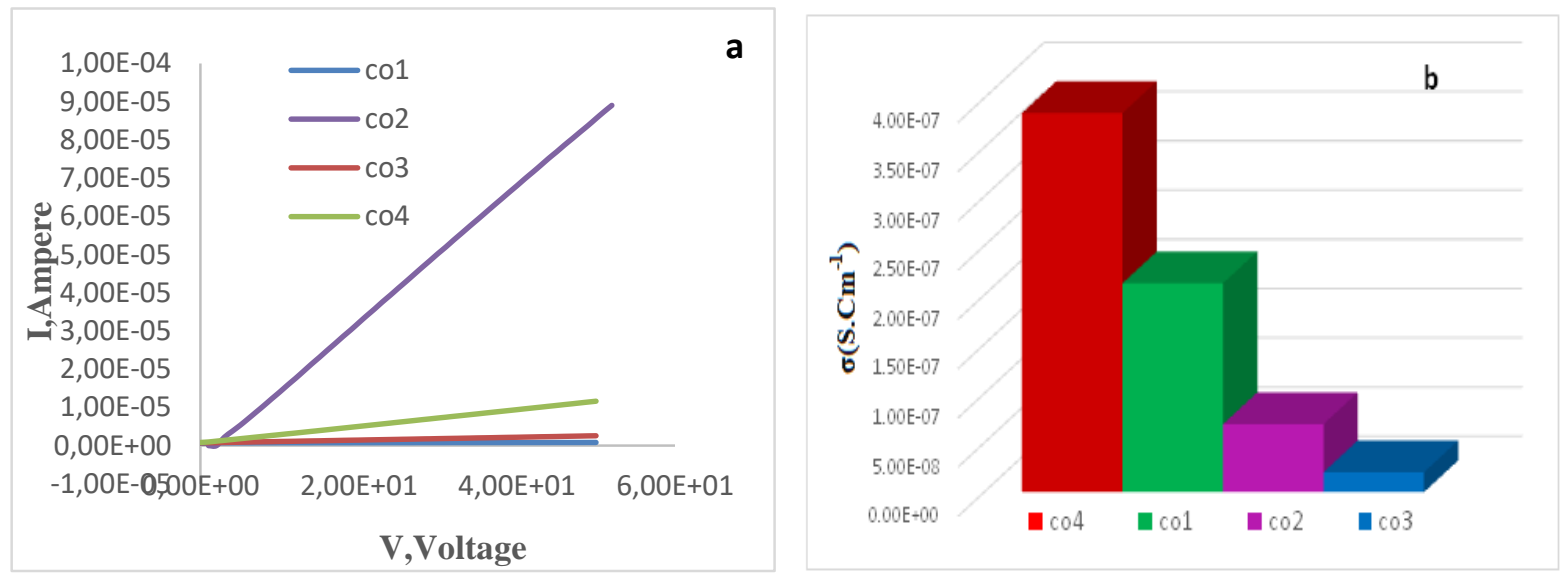

Figure 6. Electrical conductivity for $\mathrm{CO}_{1}, \mathrm{CO}_{2}, \mathrm{CO}_{3}$ and $\mathrm{co}_{4}$

\section{Conclusion}

In our search, we prepared poly (acrylonitrile-co-acrylic acid) at different ratios of $25: 75 \%, 50: 50 \%$ and $75: 25 \%$ respectively by free radical polymerization with code $\mathrm{Co}_{1}, \mathrm{CO}_{2}$ and $\mathrm{CO}_{3}$. Graft copolymerization of the 25:75 percent ratio of poly (acrylonitrile-co-acrylic acid) on chitosan was successfully performed using $\mathrm{K}_{2} \mathrm{~S}_{2} \mathrm{O}_{3}$ as an initiator in aqueous media. All samples were characterized by FTIR, XRD, and SEM. CS-g-poly (AN-AA) sample was used to remove the $\mathrm{Cd}^{++}$ion from wastewater. Adsorption effectiveness of adsorbent depended on $\mathrm{pH}$ of the solution, contact time and adsorbent dosage at room temperature. The optimum condition was $\mathrm{pH}=5,120 \mathrm{~min}$ time, and $3 \mathrm{mg} / \mathrm{L}$ adsorbent dose. It was found from the analysis of thermal stability (TGA) for all samples that due to increasing the ratio of AN, the most thermal stability sample ratio is $\mathrm{CO}_{3}$.

On the contrary, the thermal stability decreases in sample colwith high AA ratio as a result of the rapid decomposition of $-\mathrm{COOH}$ of acrylic acid. The conductivity increased by increasing the AA ratio due to increasing the number of mobile ions, according to the results of the electrical conductivity. The prepared samples can be used as an application for electrostatic dissipation between $10^{-8} \mathrm{~S} / \mathrm{cm}^{-1}-10^{-6} \mathrm{~S} / \mathrm{cm}^{-1}$.

\section{Acknowledgement:}

We would like to thank the polymer Laboratory and Petrochemical Department, Egyptian Petroleum Research Institute (EPRI) for financial support.

\section{Conflicts of interest}

The authors declare no competing financial interest.

\section{References}

1- A. Pal, D. Das, A.K. Sarkar, S. Ghorai, R. Das, and S. Pal, Synthesis of glycogen and poly (acrylic acid)based graft copolymers via ATRP and its application for selective removal of $\mathrm{Pb}^{2+}$ ions from aqueous solution, Eur. Polym. J., 2015, 66, 33-46.

2- H. Ren, Z. Gao, D. Wu, J. Jiang, Y. Sun, and C. Luo, Efficient $\mathrm{Pb}$ (II) removal using sodium alginatecarboxymethyl cellulose gel beads: Preparation, characterization, and adsorption mechanism, Carbohydr. Polym., 2016, 137, 402-409. 
3- M. Vakili, M. Rafatullah, B. Salamatinia, A.Z. Abdullah, M.H. Ibrahim, K.B. Tan, Z. Gholamic, P. Amouzgar, Application of chitosan and its derivatives as adsorbents for dye removal from water and wastewater, Carbohyd Polym., 2014, 113, 115-130.

4- J. Dai, H. Yan, H. Yang, and R. Cheng, Simple method for preparation of chitosan/poly (acrylic acid) blending hydrogel beads and adsorption of copper (II) from aqueous solutions, Chem. Eng. J., 2010, 165(1), 240-249.

5- M. Vakili, M. Rafatullah, B. Salamatinia, M.H. Ibrahim, A.Z. Abdullah, Elimination of reactive blue 4 from aqueous solutions using 3-aminopropyl triethoxysilane modified chitosan beads, Carbohydrate Polymers, 2015, 132, 89-96.

6- M. Vakili, M. Rafatullah, M.H. Ibrahim, A.Z. Abdullah, B. Salamatinia, Z. Gholami, Chitosan Hydrogel Beads Impregnated with Hexadecylamine for Improved Reactive Blue 4 Adsorption, Carbohydrate Polymer, 2016, 137, 139-146.

7- Y. Lin, Y. Hong, Q. Song, Z. Zhang, J. Gao, and T. Tao, Highly efficient removal of copper ions from water using poly (acrylic acid)-grafted chitosan adsorbent, Colloid Polym. Sci., 2017, 295(4), 627-635.

8- Z.A. Sutirman, M.M. Sanagi, and A.A.B.U. NAIM, Ammonium Persulfate-initiated Graft Copolymerization of Methacrylamide onto Chitosan: Synthesis, Characterization and Optimization, Sains Malaysiana, 2017, 46(12), 2433-2440.

9- A. Shanmugapriya, R. Ramya, S. Ramasubramaniam, and P.N. Sudha, Studies on the removal of Cr (VI) and $\mathrm{Cu}$ (II) ions using chitosan graftedpolyacrylonitrile, Arch. Appl. Sci. Res., 2011, 3(3), 424-435.

10-S.G. Mohammad, S.M. Ahmed, A.F.M. Badawi, and D.S. El-Desouki, Activated carbon derived from Egyptian banana peels for removal of cadmium from water, J. Appl. Life Sci. Int., 2015, 3(2), 77-88.

11-N. Prakash, P.N. Sudha, and N.G. Renganathan, Copper and cadmium removal from synthetic industrial wastewater using chitosan and nylon 6, Environ. Sci. Pollut. Res., 2012, 19(7), 2930-2941.

12-M.A. El-Fattah, A.M. El Saeed, A.M. Azzam, A.R.M. Abdul-Raheim, and H.H.H. Hefni, Improvement of corrosion resistance, antimicrobial activity, mechanical and chemical properties of epoxy coating by loading chitosan as a natural renewable resource, Prog. Org. Coatings, 2016, 101, 288-296.

13-E. Ismar and A.S. Sarac, Synthesis and characterization of poly (acrylonitrile-co-acrylic acid) as a precursor of carbon nanofibers, Polym. $A d v$. Technol., 2016, 27(10), 1383-1388.

14-N.S.M. Rapeia, S.A.M. Jamil, L.C. Abdullah, M.N. Mobarekeh, T.C.S. Yaw, S.J. Huey, N.A. M. Zahri, Preparation and characterization of hydrazinemodified poly (acrylonitrile-co-acrylic acid), J. Eng. Sci. Technol., 2015, 4(1), 61-70.

15-E. Guibal, Interactions of metal ions with chitosanbased sorbents: a review, Sep. Purif. Technol., 2004, $38,43-74$.

16-R.S. Acharyulu, T. Gomathi, P.N. Sudha, Physicochemical characterization of cross-linked chitosanpolyacrylonitrile polymer blends. Der Pharmacia Lettre, 2013, 5(2), 354-363.

17-D. Kumar, J. Pandey, and P. Kumar, Synthesis and characterization of modified chitosan via microwave route for novel antibacterial application, Int. J. Biol. Macromol., 2018, 107, 1388-1394.

18-S. M. Ahmed, F.I. El-Dib, N.S. El-Gendy, W.M. Sayed, and M. El-Khodary, A kinetic study for the removal of anionic sulfonated dye from aqueous solution using nano-polyaniline and Baker's yeast, Arab. J. Chem., 2016, 9, S1721-S1728.

19-E.P. Kuncoro, J. Roussy, E. Guibal, Mercury recovery by polymer-enhanced ultrafiltration: comparison of chitosan and poly(ethylenimine) used as macroligand, Sep. Sci. Technol., 2005, 40, 659-684.

20-A. Ahmad, K.B.M. Isa, and Z. Osman, Conductivity and structural studies of plasticized polyacrylonitrile (PAN)-lithium triflate polymer electrolyte films, Sains Malaysiana, 2011, 40(7), 691-694.

21-J.B. Marroquin, K.Y. Rhee, and S.J. Park, Chitosan nanocomposite films: enhanced electrical conductivity, thermal stability, and mechanical properties, Carbohydr. Polym., 2013, 92(2), 1783-1791.

22-E.M. Sadek, D.E. El-Nashar, A.A. Ward, and S.M. Ahmed, Study on the properties of multi-walled carbon nanotubes reinforced poly (vinyl alcohol) composites, J. Polym. Res., 2018, 25(12), 249. 